\title{
Investigation of the Cell Surface Proteome of Human Periodontal Ligament Stem Cells
}

\author{
Jimin Xiong, ${ }^{1,2}$ Danijela Menicanin, ${ }^{3}$ Peter S. Zilm, ${ }^{1,4}$ Victor Marino, ${ }^{1}$ \\ P. Mark Bartold, ${ }^{1}$ and Stan Gronthos ${ }^{5,6}$ \\ ${ }^{1}$ Colgate Australian Clinical Dental Research Centre, School of Dentistry, University of Adelaide, Adelaide, SA 50052, Australia \\ ${ }^{2}$ Laboratory of Tissue Regeneration and Immunology and Department of Periodontics, Beijing Key Laboratory of \\ Tooth Regeneration and Function Reconstruction, School of Stomatology, Capital Medical University, Beijing 1000443, China \\ ${ }^{3}$ School of Medicine, Faculty of Health Sciences, University of Adelaide, Adelaide, SA 50054, Australia \\ ${ }^{4}$ Oral Microbiology, School of Dentistry, University of Adelaide, Adelaide, SA 50055, Australia \\ ${ }^{5}$ Mesenchymal Stem Cell Laboratory, School of Medicine, Faculty of Health Sciences, University of Adelaide, \\ Adelaide, SA 50056, Australia \\ ${ }^{6}$ South Australian Health and Medical Research Institute, Adelaide, SA 5000, Australia
}

Correspondence should be addressed to Stan Gronthos; stan.gronthos@adelaide.edu.au

Received 27 May 2016; Accepted 3 July 2016

Academic Editor: Athina Bakopoulou

Copyright (C) 2016 Jimin Xiong et al. This is an open access article distributed under the Creative Commons Attribution License, which permits unrestricted use, distribution, and reproduction in any medium, provided the original work is properly cited.

\begin{abstract}
The present study examined the cell surface proteome of human periodontal ligament stem cells (PDLSC) compared to human fibroblasts. Cell surface proteins were prelabelled with CyDye before processing to extract the membrane lysates, which were separated using 2D electrophoresis. Selected differentially expressed protein "spots" were identified using Mass spectrometry. Four proteins were selected for validation: CD73, CD90, Annexin A2, and sphingosine kinase 1 previously associated with mesenchymal stem cells. Flow cytometric analysis found that CD73 and CD90 were highly expressed by human PDLSC and gingival fibroblasts but not by keratinocytes, indicating that these antigens could be used as potential markers for distinguishing between mesenchymal cells and epithelial cell populations. Annexin A2 was also found to be expressed at low copy number on the cell surface of human PDLSC and gingival fibroblasts, while human keratinocytes lacked any cell surface expression of Annexin A2. In contrast, sphingosine kinase 1 expression was detected in all the cell types examined using immunocytochemical analysis. These proteomic studies form the foundation to further define the cell surface protein expression profile of PDLSC in order to better characterise this cell population and help develop novel strategies for the purification of this stem cell population.
\end{abstract}

\section{Introduction}

Despite encouraging outcomes, therapeutic utilization of mesenchymal stem cells (MSC) is constrained by the lack of understanding and definition of their properties and developmental status following ex vivo expansion. Heterogeneity inherent within progenitor populations presents as one of the major limitations to their clinical application in regenerative medicine. The variability and inconsistencies in cellular properties allude to a hierarchical order within stem cell populations and result in the coexistence of subsets of distinct morphologies, phenotypes, proliferation rates, and biological functions [1-3]. Currently, there is a lack of individual or a set of markers that can distinguish different subsets within MSClike populations of different origins from more differentiated fibroblastic cells in any tissue.

Identification of stem/progenitor cells residing in the periodontium [4-6] has offered a potential novel therapeutic avenue for treating periodontal tissues damaged due to trauma, injury, and disease. Periodontal diseases are highly prevalent among all human populations and if untreated cause the destruction of periodontal supporting tissues and can potentially result in tooth loss. Predictable regeneration of periodontal tissues as a result of advanced periodontal diseases is beyond the scope of current technologies and, therefore, alternative strategies are being investigated. 
In addition to periodontal ligament stem cells (PDLSC), the periodontium contains multiple cell types including fibroblasts, endothelial cells, epithelial cell rests of Malassez (ERM), osteoblasts, and cementoblasts [7]. This array of specialised cell types is integrated into and cofunctions to provide the periodontium with its essential and unique structural and mechanical properties. This biological complexity and cellular heterogeneity highlights the need for identification of surface markers specific to each cell subset within the periodontium to enable identification and discriminant isolation of desired and required cell populations.

It has been demonstrated that PDLSC share a phenotypic profile characteristic of bone marrow derived mesenchymal stem cells (BMSC) including expression of BMSC markers CD29, CD44, CD90, and CD105 [8]. Furthermore, PDLSC express the early BMSC and perivascular cell surface markers STRO-1 and CD146/MUC18 [4], with a subset of progenitors presenting with other antigens associated with perivascular tissues (alpha-smooth muscle actin and pericyte-associated antigen, 3G5) [9]. Together, these findings designate a possible perivascular origin of PDLSC, in accord with earlier findings by McCulloch and colleagues [10, 11]. In conjunction, comparative genomic analyses identified unique features exhibited by PDLSC when compared to BMSC and dental pulp stem cells (DPSC). These studies demonstrated increased levels of scleraxis (a tendon-specific transcription factor) [4] and PLAP-1 (periodontal ligament associated protein-1/asporin) expression in PDLSC [12]. A panel of markers, proposed for the current identification of PDLSC, includes alkaline phosphatase, type I collagen, periostin, runt-related transcription factor-2 (Runx2), and epithelial growth factor receptor, which are also expressed by BMSC, considering that both cell populations commonly hold the innate capacity for formation of mineralized matrix in the form of cementum and bone, respectively [13]. Since the cell surface markers described above are ubiquitously expressed by MSC-like populations derived from all dental tissues, specific cell surface antigens, capable of distinguishing between individual dental stem cell population subsets, are yet to be identified [14]. Therefore, our understanding of the cell surface phenotype of PDLSC falls short when considering the need to isolate and purify stem/progenitor cell subsets from the heterogeneous PDL population. This has driven the use of proteomics, the technology investigating global protein expression, to characterise the cell surface phenotype of PDLSC.

Proteomic studies investigating dental tissues have been summarized by McCulloch [15]. While the majority of studies focused on protein expression by periodontal microbiota [16-18], a limited number of papers examined proteomic profiles of periodontal ligament cells and tissues [15]. In this study, we provide an insight into the cell surface proteome of PDLSC to identify potential discriminatory PDLSC markers not expressed by other cells residing in the periodontium.

\section{Methods and Materials}

2.1. Isolation of Human PDLSC and Gingival Fibroblasts. Human PDLSC and gingival fibroblasts (GF) were isolated from three donors and cultured as previously described (Human Research Ethics Committee of the University of Adelaide, Approval Number H-112-2008) [4, 19]. Briefly, gingival and periodontal ligament tissues were collected from excised gingiva and middle third of the root, respectively. The tissues were digested in equal volumes of collagenase type I $(3 \mathrm{mg} / \mathrm{mL}$; Worthington Biochemical, Lakewood, NJ) and dispase type II $(4 \mathrm{mg} / \mathrm{mL}$; Roche Diagnostics, Indianapolis, IN) for 2 hours at $37^{\circ} \mathrm{C}$. Isolated cells were maintained and cultured in modified $\alpha$-MEM media ( $\alpha$-MEM; SigmaAldrich, St. Louis, MO, USA) supplemented with 10\% FCS (Thermo Electron, Melbourne, VIC, Australia), $50 \mathrm{U} / \mathrm{mL}$ and $50 \mu \mathrm{g} / \mathrm{mL}$ penicillin and streptomycin (Sigma-Aldrich), $1 \mathrm{mM}$ sodium pyruvate, $2 \mathrm{mM}$ L-glutamine (SAFC, Lenexa, KS, USA), and $100 \mu \mathrm{M}$ L-ascorbate-2-phosphate (Novachem, Melbourne, VIC, Australia) at $37^{\circ} \mathrm{C}$ and $5 \% \mathrm{CO}_{2}$ in a humidified environment, with a twice-weekly medium change. Cells were harvested and further expanded once upon reaching confluence. This process was repeated when cells reached $80 \%$ confluence until desired cell numbers were obtained.

Human neonatal foreskins, collected from routine circumcisions, were used to isolate epithelial sheets after overnight incubation with $4 \mathrm{mg} / \mathrm{mL}$ dispase at $4^{\circ} \mathrm{C}$, followed by trypsinization for $5 \mathrm{~min}$ at $37^{\circ} \mathrm{C}$ to obtain basal keratinocytes. Keratinocytes were cultured in DMEM containing 10\% fetal calf serum, $20 \mathrm{ng} / \mathrm{mL}$ epidermal growth factor (SigmaAldrich), and $0.4 \mu \mathrm{g} / \mathrm{mL}$ hydrocortisone (Sigma-Aldrich), at $37^{\circ} \mathrm{C}$ and $5 \% \mathrm{CO}_{2}$ in a humidified environment, with a twiceweekly medium change.

2.2. Immunohistochemistry. Chamber slides (Nalge-Nunc Lab-Tek, Rochester, NY, USA) were seeded with $8 \times 10^{3}$ cells per $\mathrm{cm}^{2}$, in media with additives for 2 days. The slides were fixed with $4 \%$ paraformaldehyde (PFA) and endogenous peroxidase activity was inhibited using $0.5 \% \mathrm{H}_{2} \mathrm{O}_{2}$ in methanol. The sections were incubated with primary antibodies or isotype control antibodies overnight at $4^{\circ} \mathrm{C}$, secondary antibodies for 1 hour at room temperature, Vectastain ABC Reagents (Vector Laboratories, Burlingame, CA, USA) according to the manufacturer's recommendations, or horseradish-peroxidase-labelled streptavidin (Promega, Madison, WI, USA) at 1 in 1000 dilution and then developed with diaminobenzidine (Dako, Campbellfield, VIC, Australia). The slides were counterstained briefly with haematoxylin (ProSciTech, Thuringowa Central, QLD, Australia). Antibodies used in this study are 1B5, mouse IgG1 isotype control (1:25; Professor L. K. Ashman, University of Newcastle, NSW, Australia); mouse IgG1 anti-human CD73 (1:25; BD Pharmingen, Sparks, MD, USA); mouse IgG1 anti-human CD90 (1:25; BD Pharmingen); mouse IgG1 anti-human Annexin A2 (1:12.5; Invitrogen, Waltham, MA, USA); rabbit anti-human sphingosine kinase $1(1: 20$; Cayman Chemical, Ann Arbor, MI, USA); normal rabbit Ig (1:20; Vector Laboratories, Burlingame, CA, USA); goat anti-mouse IgG biotin secondary antibody $(1: 200$; Southern Biotechnology Associates, Birmingham, AL); and goat anti-rabbit IgG biotin secondary antibody ( $1: 150$; Vector Laboratories). 
2.3. Immunophenotypic Profiling. Single cell suspensions of $2 \times 10^{5}$ cells were blocked with $5 \%$ FCS, $1 \%$ bovine serum albumin (BSA, SAFC), $50 \mathrm{U} / \mathrm{mL}$ penicillin, $50 \mu \mathrm{g} / \mathrm{mL}$ streptomycin, and 5\% normal human serum (Red Cross, SA, Australia) in HBSS on ice. Cells were treated with primary or isotype control antibodies (CD73, CD90, and Annexin A2) at a concentration of $20 \mu \mathrm{g} / \mathrm{mL}$, followed by incubation with phycoerythrin (PE) conjugated goat anti-mouse IgG1 $(1: 50$; Southern Biotechnology Associates). Samples were fixed in PBS with $0.1 \%$ formalin and $20 \mathrm{mg} / \mathrm{mL}$ glucose. Analysis was performed on a fluorescence-activated cell sorter fitted with $250 \mathrm{MW}$ argon laser (Beckman Coulter Cytomics FC500, using CXP Cytometry List Mode Data Acquisition and Analysis Software version 2.2; Beckman Coulter, Miami, FL, USA).

2.4. Proteomic Analysis. All equipment and reagents were purchased from Bio-Rad Laboratories (Hercules, CA, USA) unless stated otherwise. CyDye DIGE Fluor minimal dye was purchased from GE Healthcare (Buckinghamshire, UK).

\subsection{Cell Surface Labelling Using CyDye DIGE Fluor Minimal} Dye. CyDye fluorescent cell surface protein labelling was performed as previously reported $[4,20]$. Briefly, approximately 20 million subconfluent PDLSC or GF were detached with either $1 \mathrm{mM}$ PUCK's EDTA or $3 \mathrm{mg} / \mathrm{mL}$ type I collagenase and aliquoted into $\sim 5$ million cells per tube. Cells were washed in ice cold HBSS ( $\mathrm{pH}$ 7.4) followed by ice cold HBSS ( $\mathrm{pH}$ 8.5) and centrifuged at $800 \times \mathrm{g}$ for 2 minutes. The cell pellets were resuspended in $200 \mu \mathrm{L}$ labelling buffer containing HBSS ( $\mathrm{pH}$ 8.5) and $1 \mathrm{M}$ urea. Cells were then labelled with $600 \mathrm{pmol}$ of either Cy2, Cy3, or Cy5 or CyDye DIGE Fluor minimal dyes on ice in the dark for 20 minutes. Staining was quenched by adding $20 \mu \mathrm{L}$ lysine $(10 \mathrm{mM})$ for 10 minutes. Surface-labelled cells were pelleted by centrifugation and resuspended in $202 \mu \mathrm{L} \mathrm{HBSS}$ (pH 7.4). An aliquot $(2 \mu \mathrm{L})$ was taken prior to and after labelling to check for labelling efficiency using flow cytometry.

2.6. Membrane Protein Enrichment. Proteins were isolated and fractionated using a phase separation kit (Mem-PER, Pierce, Rockford, IL, USA) according to the manufacturer's instructions. Briefly, $150 \mu \mathrm{L}$ reagent A containing $1 \mu \mathrm{L}$ protease inhibitor (Sigma) was added to cell pellets containing PDLSC or GF. Following 10-minute incubation, $450 \mu \mathrm{L}$ mixture of reagents $B$ and $C$ was added to cell lysates and tubes were kept on ice for 30 minutes. The preparation was centrifuged at $10,000 \times \mathrm{g}$ for 3 minutes, at $4^{\circ} \mathrm{C}$, and the supernatant was incubated at $37^{\circ} \mathrm{C}$ for 20 minutes. Following centrifugation at $10,000 \times \mathrm{g}$ and phase separation, the hydrophobic fraction containing membrane proteins was carefully removed and purified using ReadyPrep 2-D Cleanup Kit. Membrane protein enrichment efficiency was assessed and cells were subjected to up to three membrane fractionation steps.

2.7. Membrane Protein Separation by Two-Dimensional Gel Electrophoresis (2DE). Membrane proteins were solubilised
TABLE 1: IEF conditions for $11 \mathrm{~cm}$ IPG (3-10).

\begin{tabular}{|c|c|c|c|}
\hline Step number & Voltage & Voltage ramping mode & Time \\
\hline Step 1 & $150 \mathrm{~V}$ & Linear & 1 hour \\
\hline Step 2 & $300 \mathrm{~V}$ & Linear & 2.30 hours \\
\hline Step 3 & $600 \mathrm{~V}$ & Linear & 1.50 hours \\
\hline Step 4 & $1200 \mathrm{~V}$ & Linear & 1.50 hours \\
\hline Step 5 & $4000 \mathrm{~V}$ & Slow & 1.50 hours \\
\hline Step 6 & $8000 \mathrm{~V}$ & Slow & 1 hour \\
\hline Step 7 & $8000 \mathrm{~V}$ & Linear & 30000 volt-hours \\
\hline Step 8 & $500 \mathrm{~V}$ & Slow & 0.15 hours \\
\hline
\end{tabular}

with ReadyPrep reagent 3 buffer for 1 hour at room temperature. The protein was solubilised by gentle aspiration through a fine-gauge needle, as previously described by Zilm et al. [21]. The protein concentration was determined using RC/DC Protein Assay Kit according to the manufacturer's instructions. Proteins were separated in the first dimension using $11 \mathrm{~cm}$ immobilised pH gradient (IPG) strips ( $\mathrm{pH} 3-10$ ) which had been passively rehydrated for 24 hours in $330 \mu \mathrm{L}$ rehydration/extraction buffer $\# 3$, containing $0.2 \%(\mathrm{w} / \mathrm{v}) \mathrm{pH}$ 3-10 ampholytes and $1.2 \%(\mathrm{v} / \mathrm{v})$ De-Streak Reagent (GE Healthcare, Buckinghamshire, UK). IEF was performed using a Protean IEF cell. Briefly, membrane protein preparations containing $150 \mu \mathrm{g}$ protein were cup-loaded onto the anode end of the IPG strip. The IEF cycle consisted of 8 steps outlined in Table 1, with a $50 \mu \mathrm{A} /$ strip current limit, and the temperature was maintained at $20^{\circ} \mathrm{C}$. Duplicate IPG strips were run concurrently. Following IEF, the IPG strips were equilibrated as previously described [22]. Polyacrylamide gels $(18 \times 18 \mathrm{~cm})$ containing $8 \% \mathrm{~T}, 3.3 \% \mathrm{C}, 0.1 \% \mathrm{SDS}$, and $375 \mathrm{mM}$ Tris/ $\mathrm{HCl}(\mathrm{pH} 8.8)$ were cast without stacking gels using a Protean II XL casting chamber. Proteins were separated in the second dimension using a Protean II XL Multicell (Bio-Rad Laboratories) in tris-glycine tank buffer ( $25 \mathrm{mM}$ Tris, $192 \mathrm{mM}$ glycine, and $0.1 \%(\mathrm{w} / \mathrm{v}) \mathrm{SDS}$ ) and resolved at $7 \mathrm{~mA} / \mathrm{gel}$.

2.8. Gel Visualisation. Gels were scanned using a Typhoon Trio Variable Mode Imager (Molecular Dynamics Inc., Sunnyvale, CA) with a pixel resolution of $100 \mu \mathrm{m}$ at the CyDye excitation and emission wavelengths described by the manufacturer. Image analysis was performed using PDQuest software (version 7.2, Bio-Rad Laboratories). Replicate groups, each containing four gels, were used for analysis. Protein spots were automatically detected and manually edited. Gel staining was normalized using the total density in gels.

2.9. Flamingo Fluorescent Staining. To visualise all proteins, gels were fixed in $40 \%$ ethanol $(\mathrm{v} / \mathrm{v}) / 10 \%$ acetic acid $(\mathrm{v} / \mathrm{v})$ in Milli-Q water and stained with Flamingo Fluorescent Stain (Bio-Rad Laboratories) according to the manufacturer's instructions. Gels were destained in $0.1 \%(\mathrm{v} / \mathrm{v})$ Tween 20 in Milli-Q water for 10 minutes prior to imaging. Gels were scanned using a Typhoon Trio Variable Mode Imager using a green laser $(532 \mathrm{~nm})$ excitation source and $610 \pm 30 \mathrm{~nm}$ bandpass emission filter. 
2.10. Automated Spot Picking. Gel images were scanned using a Typhoon Trio Variable Mode Imager and imported into DeCyder software (version 6.5, GE Healthcare) and spots were detected using the automated method. Spots of interest were selected to generate a pick-list. The pick-list was exported from DeCyder and imported into Spot Picker software (version 1.2, GE Healthcare). Spots were excised using the Ettan Spot Cutting Robot (GE Healthcare) according to the manufacturer's instructions. Gel plugs were washed twice with $0.1 \mathrm{M}$ ammonium bicarbonate buffer $\left(\mathrm{NH}_{4} \mathrm{HCO}_{3}\right)$, followed by Milli-Q water, then dehydrated in acetonitrile $(\mathrm{ACN})$, and dried.

2.11. Protein Identification by Liquid Chromatography-Electrospray Ionisation-Ion Trap (LC-ESI-IT) Mass Spectrometry (MS). Each gel plug was digested with $10 \mu \mathrm{L}$ of $5 \mathrm{mM}$ ammonium bicarbonate with $10 \%$ ACN containing 100 ng trypsin (Promega) for 16 hours at $37^{\circ} \mathrm{C}$. Peptides were extracted sequentially with $1 \%$ formic acid (FA), 50\% ACN/0.1\% FA, and $\mathrm{ACN}$, and the combined extracts were concentrated by centrifugal evaporation and diluted in $6 \mu \mathrm{L} \mathrm{3 \%} \mathrm{ACN/0.1 \%}$ FA. Vacuum concentrated samples were resuspended in $0.1 \%$ $\mathrm{FA}$ in $2 \% \mathrm{ACN}$ to a total volume of $\sim 8 \mu \mathrm{L}$. LC-ESI-IT MS/MS was performed using an online 1100 series HPLC system (Agilent Technologies) and HCT Ultra 3D-Ion Trap mass spectrometer (Bruker Daltonics). The LC system was interfaced to the MS using an Agilent Technologies Chip Cube operating with a ProtID-Chip-150 (II), which integrates the enrichment column (Zorbax 300SB-C18, $4 \mathrm{~mm}, 40 \mathrm{~nL}$ ), analytical column (Zorbax $300 \mathrm{SB}-\mathrm{C18}, 150 \mathrm{~mm} \times 75 \mu \mathrm{m}$ ), and nanospray emitter. $5 \mu \mathrm{L}$ samples were loaded onto the enrichment column set at a flow rate of $4 \mu \mathrm{L} / \mathrm{min}$ in Mobile Phase A (0.1\% FA in 2\% v/v ACN) and resolved with $1-30 \%$ gradient of Mobile Phase B (0.1\% FA in $98 \% \mathrm{w} / \mathrm{v}$ ACN) over 32 minutes at $300 \mathrm{~nL} / \mathrm{min}$. Ionizable species $(300<\mathrm{m} / z<$ $3,000)$ were trapped and the two most intense ions eluting at the time were fragmented by collision-induced dissociation. Active exclusion was used to exclude a precursor ion for 30 seconds following the acquisition of two spectra.

2.12. Protein Identification Using Web-Based Bioinformatics Tools. MS and MS/MS spectra were subjected to peak detection and deconvolution using Data Analysis (version 3.4, Bruker Daltonics, Billerica, MA, USA). Compound lists were exported into BioTools (version 3.1, Bruker Daltonics) and then submitted to Mascot (version 2.2, Boston, MA, USA) using the following parameters: fixed modification = carbamidomethyl $(\mathrm{C})$, variable modification = oxidation $(\mathrm{M})$, MS mass tolerance $=1.5 \mathrm{Da}, \mathrm{MS} / \mathrm{MS}$ mass tolerance $=0.8 \mathrm{Da}$, peptide charge $=1+, 2+$, or $3+$, and missed cleavages $=3$. Data were matched to the Swiss-Prot protein database.

\section{Results}

3.1. Membrane Protein Expression of Ex Vivo Expanded Human PDLSC. CyDye-tagged membrane-associated proteins derived from human PDLSC following ex vivo expansion were separated by 2-dimensional electrophoresis. Based on the CyDye imaging, a total of 80 well-resolved proteins spots

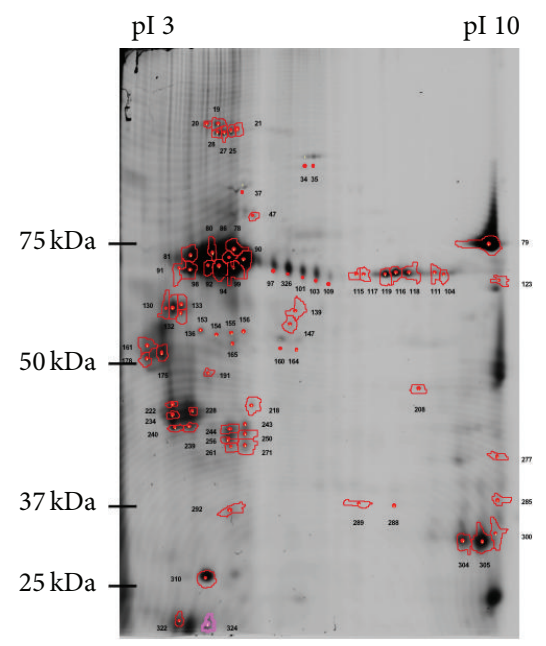

FIGURE 1: Representative raw 2DE gel of CyDye labelled proteins of ex vivo expanded human periodontal ligament stem cells and the location of proteins identified on the raw 2DE image. Following cell surface labelling with CyDye and membrane protein enrichment, proteins were separated by $2 \mathrm{DE}$ using a $\mathrm{pI}$ range of $\mathrm{pH} 3-10$ and a molecular weight range of $10-110 \mathrm{kDa}$. Following image analysis, 80 well-resolved protein spots were detected. A total of 32 membraneassociated protein spots were consistently found on replicate gels.

with a molecular weight range of $10-110 \mathrm{kDa}$ were detected after automatic exclusion of pseudospots and the locations of the identified protein spots on the representative raw image are shown in Figure 1.

3.2. Identification of Proteins Expressed by Human PDLSC. Following spot excision and analysis by mass spectrometry, a total of 32 protein spots were identified as membraneassociated proteins (Figure 1). Table 2 outlines the details of the membrane-associated proteins, including the protein name, spot number, predicted molecular weight and pI values, ID/total queries, combined ion scores, and coverage. Some proteins were identified in multiple spots (e.g., $5^{\prime}$ nucleotidase, Annexin A2, and sphingosine kinase 1) suggesting the presence of isoforms, possibly as a result of posttranslational modifications. Differences in the observed molecular weight/pI and the expected values were observed in some proteins (e.g., sphingosine kinase 1), possibly due to posttranslational modifications, proteolysis, or protein aggregation. Importantly, this approach was validated by the identification of MSC-associated stem cell surface proteins, $5^{\prime}$-nucleotidase (CD73) and Thy-1 membrane glycoprotein (CD90), previously shown to be expressed by PDLSC [8]. Furthermore, MS identified other membrane-associated markers, such as Annexin A2 and sphingosine kinase 1, the expression of which had not previously been reported by human PDLSC. All four proteins were chosen for further confirmatory analyses.

3.3. Validation of the Expression of $5^{\prime}$-Nucleotidase, Thy-1 Membrane Glycoprotein, Annexin A2, and Sphingosine Kinase 1. To confirm the expression of selected proteins including 
TABLE 2: Membrane-associated proteins on human PDLSC.

\begin{tabular}{|c|c|c|c|c|c|c|}
\hline $\begin{array}{l}\text { Swiss-Prot } 57.7 \\
\text { Accession number }\end{array}$ & Protein name & $\begin{array}{c}\text { Spot } \\
\text { number }\end{array}$ & $\begin{array}{c}\text { Predicted } \\
\text { MW } \\
(\mathrm{kDa}) / \mathrm{pI}\end{array}$ & $\begin{array}{l}\text { ID/total } \\
\text { queries }\end{array}$ & $\begin{array}{l}\text { Combined } \\
\text { ion scores }\end{array}$ & $\begin{array}{l}\text { Coverage } \\
(\%)\end{array}$ \\
\hline 1A01_HUMAN & $\begin{array}{l}\text { HLA class I histocompatibility } \\
\text { antigen, A-1 alpha chain }\end{array}$ & 243 & $41.1 / 6.1$ & $2 / 612$ & 66 & 10 \\
\hline 1C06_HUMAN & $\begin{array}{l}\text { HLA class I histocompatibility } \\
\text { antigen, Cw- } 6 \text { alpha chain }\end{array}$ & 239 & $41.4 / 5.7$ & $4 / 638$ & 175 & 18 \\
\hline \multirow{11}{*}{ 5NTD_HUMAN } & \multirow{11}{*}{$5^{\prime}$-Nucleotidase } & 78 & $63.9 / 6.6$ & $13 / 518$ & 287 & 17 \\
\hline & & 80 & $63.9 / 6.6$ & $8 / 513$ & 206 & 11 \\
\hline & & 90 & $63.9 / 6.6$ & $41 / 546$ & 872 & 32 \\
\hline & & 99 & $63.9 / 6.6$ & $13 / 535$ & 191 & 15 \\
\hline & & 101 & $63.9 / 6.6$ & $39 / 517$ & 945 & 38 \\
\hline & & 103 & $63.9 / 6.6$ & $42 / 539$ & 933 & 33 \\
\hline & & 109 & $63.9 / 6.6$ & $25 / 536$ & 606 & 22 \\
\hline & & 111 & $63.9 / 6.6$ & $2 / 558$ & 34 & 6 \\
\hline & & 326 & $63.9 / 6.6$ & $53 / 544$ & 961 & 35 \\
\hline & & 86 & $63.9 / 6.6$ & $25 / 356$ & 521 & 31 \\
\hline & & 97 & $63.9 / 6.6$ & $45 / 414$ & 1044 & 39 \\
\hline AMPB_HUMAN & Aminopeptidase B & 94 & $73.2 / 5.5$ & $5 / 559$ & 172 & 10 \\
\hline \multirow{5}{*}{ ANXA2_HUMAN } & \multirow{5}{*}{ Annexin A2 } & 285 & $38.8 / 7.6$ & $36 / 581$ & 489 & 47 \\
\hline & & 288 & $38.8 / 7.6$ & $87 / 585$ & 1907 & 67 \\
\hline & & 289 & $38.8 / 7.6$ & $56 / 600$ & 950 & 55 \\
\hline & & 292 & $38.8 / 7.6$ & $3 / 594$ & 76 & 11 \\
\hline & & 304 & $38.8 / 7.6$ & $14 / 536$ & 241 & 28 \\
\hline \multirow{3}{*}{ CAP2_HUMAN } & \multirow{3}{*}{$\begin{array}{l}\text { Adenylyl cyclase-associated } \\
\text { protein } 2\end{array}$} & 154 & $53.1 / 6.0$ & $2 / 576$ & 67 & 6 \\
\hline & & 156 & $53.1 / 6.0$ & $4 / 557$ & 102 & 8 \\
\hline & & 165 & $53.1 / 6.0$ & $3 / 619$ & 102 & 11 \\
\hline CO1A1_HUMAN & Collagen alpha-1(I) chain & 292 & $139.9 / 5.6$ & $7 / 594$ & 103 & 4 \\
\hline CO6A3_HUMAN & Collagen alpha-3(VI) chain & 20 & $345.2 / 6.3$ & $9 / 568$ & 159 & 3 \\
\hline DNJA1_HUMAN & $\begin{array}{l}\text { DnaJ homolog subfamily A } \\
\text { member } 1\end{array}$ & 208 & $45.6 / 6.6$ & $4 / 521$ & 95 & 12 \\
\hline EHD3_HUMAN & EH domain-containing protein 3 & 139 & $62.0 / 6.1$ & $4 / 600$ & 71 & 8 \\
\hline EZRI_HUMAN & Ezrin & 65 & $69.5 / 5.9$ & $28 / 558$ & 455 & 26 \\
\hline \multirow{5}{*}{ FLNC_HUMAN } & \multirow{5}{*}{ Filamin-C } & 29 & $293.4 / 5.6$ & $4 / 492$ & 49 & 2 \\
\hline & & 78 & $293.4 / 5.6$ & $3 / 518$ & 65 & 1 \\
\hline & & 139 & $293.4 / 5.6$ & $14 / 600$ & 363 & 6 \\
\hline & & 147 & $293.4 / 5.6$ & $13 / 525$ & 237 & 4 \\
\hline & & 191 & $293.4 / 5.6$ & $4 / 586$ & 147 & 2 \\
\hline GELS_HUMAN & Gelsolin & 46 & $86.0 / 5.9$ & $46 / 636$ & 1011 & 35 \\
\hline \multirow{17}{*}{ K2C1_HUMAN } & \multirow{17}{*}{ Keratin, type II cytoskeletal 1} & 25 & $66.2 / 8.2$ & $5 / 578$ & 128 & 9 \\
\hline & & 46 & $66.2 / 8.2$ & $11 / 636$ & 456 & 17 \\
\hline & & 47 & $66.2 / 8.2$ & $7 / 491$ & 170 & 7 \\
\hline & & 80 & $66.2 / 8.2$ & $11 / 513$ & 227 & 13 \\
\hline & & 91 & $66.2 / 8.2$ & $3 / 666$ & 94 & 12 \\
\hline & & 94 & $66.2 / 8.2$ & $4 / 559$ & 146 & 8 \\
\hline & & 98 & $66.2 / 8.2$ & $2 / 639$ & 57 & 7 \\
\hline & & 104 & $66.2 / 8.2$ & $2 / 520$ & 80 & 3 \\
\hline & & 111 & $66.2 / 8.2$ & $5 / 558$ & 79 & 10 \\
\hline & & 130 & $66.2 / 8.2$ & $3 / 614$ & 60 & 8 \\
\hline & & 147 & $66.2 / 8.2$ & $20 / 525$ & 256 & 13 \\
\hline & & 153 & $66.2 / 8.2$ & $2 / 615$ & 126 & 7 \\
\hline & & 154 & $66.2 / 8.2$ & $3 / 576$ & 107 & 8 \\
\hline & & 228 & $66.2 / 8.2$ & $10 / 664$ & 466 & 22 \\
\hline & & 289 & $66.2 / 8.2$ & $14 / 600$ & 386 & 15 \\
\hline & & 292 & $66.2 / 8.2$ & $2 / 594$ & 55 & 3 \\
\hline & & 324 & $66.2 / 8.2$ & $5 / 570$ & 127 & 10 \\
\hline
\end{tabular}


TABLE 2: Continued.

\begin{tabular}{|c|c|c|c|c|c|c|}
\hline $\begin{array}{l}\text { Swiss-Prot } 57.7 \\
\text { Accession number }\end{array}$ & Protein name & $\begin{array}{c}\text { Spot } \\
\text { number }\end{array}$ & $\begin{array}{c}\text { Predicted } \\
\text { MW } \\
(\mathrm{kDa}) / \mathrm{pI}\end{array}$ & $\begin{array}{l}\text { ID/total } \\
\text { queries }\end{array}$ & $\begin{array}{l}\text { Combined } \\
\text { ion scores }\end{array}$ & $\begin{array}{c}\text { Coverage } \\
(\%)\end{array}$ \\
\hline KAP2_HUMAN & $\begin{array}{l}\text { cAMP-dependent protein kinase } \\
\text { type II-alpha regulatory subunit }\end{array}$ & 178 & $45.8 / 5.0$ & $13 / 621$ & 360 & 22 \\
\hline \multirow{5}{*}{ NOMO2_HUMAN } & \multirow{5}{*}{ Nodal modulator 2} & 19 & $140.4 / 5.5$ & $9 / 599$ & 244 & 8 \\
\hline & & 20 & $140.4 / 5.5$ & $10 / 568$ & 189 & 12 \\
\hline & & 25 & $140.4 / 5.5$ & $10 / 578$ & 226 & 8 \\
\hline & & 27 & $140.4 / 5.5$ & $11 / 583$ & 224 & 10 \\
\hline & & 28 & $140.4 / 5.5$ & $11 / 436$ & 244 & 12 \\
\hline NUCB2_HUMAN & Nucleobindin-2 & 178 & $50.3 / 5.0$ & $3 / 621$ & 100 & 5 \\
\hline \multirow{2}{*}{ PDIA6_HUMAN } & \multirow{2}{*}{ Protein disulfide-isomerase A6 } & 175 & $48.5 / 5.0$ & $6 / 592$ & 209 & 12 \\
\hline & & 178 & $48.5 / 5.0$ & $7 / 621$ & 278 & 10 \\
\hline RUVB2_HUMAN & RuvB-like 2 & 191 & $51.3 / 5.5$ & $25 / 586$ & 614 & 34 \\
\hline SBP1_HUMAN & Selenium-binding protein 1 & 165 & $52.9 / 5.9$ & $7 / 619$ & 126 & 8 \\
\hline SNX4_HUMAN & Sorting nexin-4 & 155 & $52.2 / 5.7$ & $5 / 637$ & 157 & 14 \\
\hline \multirow{4}{*}{ SPHK1_HUMAN } & \multirow{4}{*}{ Sphingosine kinase 1} & 19 & $42.9 / 6.6$ & $12 / 599$ & 253 & 18 \\
\hline & & 20 & $42.9 / 6.6$ & $5 / 568$ & 188 & 16 \\
\hline & & 21 & $42.9 / 6.6$ & $4 / 518$ & 138 & 11 \\
\hline & & 34 & $42.9 / 6.6$ & $3 / 517$ & 200 & 11 \\
\hline \multirow{2}{*}{ STML2_HUMAN } & \multirow{2}{*}{ Stomatin-like protein 2} & 239 & $38.6 / 6.9$ & $13 / 638$ & 584 & 37 \\
\hline & & 240 & $38.6 / 6.9$ & $6 / 656$ & 266 & 27 \\
\hline \multirow{2}{*}{ STXB3_HUMAN } & \multirow{2}{*}{ Syntaxin-binding protein 3} & 111 & $68.6 / 8.0$ & $5 / 558$ & 97 & 7 \\
\hline & & 118 & $68.6 / 8.0$ & $6 / 479$ & 103 & 7 \\
\hline \multirow{2}{*}{ SWP70_HUMAN } & \multirow{2}{*}{ Switch-associated protein 70} & 94 & $69.4 / 5.7$ & $3 / 559$ & 80 & 5 \\
\hline & & 99 & $69.4 / 5.7$ & $6 / 535$ & 136 & 7 \\
\hline THY1_HUMAN & Thy-1 membrane glycoprotein & 304 & $18.2 / 9.0$ & $3 / 536$ & 55 & 16 \\
\hline \multirow{4}{*}{ UBP14_HUMAN } & \multirow{4}{*}{$\begin{array}{l}\text { Ubiquitin carboxyl-terminal } \\
\text { hydrolase } 14\end{array}$} & 130 & $56.5 / 5.2$ & $6 / 614$ & 176 & 15 \\
\hline & & 132 & $56.5 / 5.2$ & $8 / 611$ & 184 & 18 \\
\hline & & 133 & $56.5 / 5.2$ & $3 / 635$ & 100 & 5 \\
\hline & & 136 & $56.5 / 5.2$ & $15 / 642$ & 372 & 24 \\
\hline ULA1_HUMAN & $\begin{array}{l}\text { NEDD8-activating enzyme E1 } \\
\text { regulatory subunit }\end{array}$ & 133 & $60.7 / 5.2$ & $6 / 635$ & 127 & 8 \\
\hline \multirow{3}{*}{ VATB2_HUMAN } & \multirow{3}{*}{$\begin{array}{l}\text { V-type proton ATPase subunit B, } \\
\text { brain isoform }\end{array}$} & 153 & $56.8 / 5.6$ & $4 / 615$ & 191 & 12 \\
\hline & & 154 & $56.8 / 5.6$ & $9 / 576$ & 252 & 14 \\
\hline & & 155 & $56.8 / 5.6$ & $7 / 637$ & 300 & 16 \\
\hline \multirow{3}{*}{ VDAC1_HUMAN } & \multirow{3}{*}{$\begin{array}{l}\text { Voltage-dependent } \\
\text { anion-selective channel protein } 1\end{array}$} & 300 & $30.9 / 8.6$ & $7 / 601$ & 128 & 18 \\
\hline & & 304 & $30.9 / 8.6$ & $34 / 536$ & 902 & 59 \\
\hline & & 305 & $30.9 / 8.6$ & $19 / 524$ & 319 & 38 \\
\hline \multirow{8}{*}{ VIME_HUMAN } & \multirow{8}{*}{ Vimentin } & 130 & $53.7 / 5.1$ & $2 / 614$ & 68 & 6 \\
\hline & & 161 & $53.7 / 5.1$ & $28 / 626$ & 710 & 46 \\
\hline & & 175 & $53.7 / 5.1$ & $44 / 592$ & 1026 & 63 \\
\hline & & 178 & $53.7 / 5.1$ & $46 / 621$ & 1306 & 58 \\
\hline & & 222 & $53.7 / 5.1$ & $3 / 630$ & 87 & 6 \\
\hline & & 228 & $53.7 / 5.1$ & $5 / 664$ & 139 & 9 \\
\hline & & 239 & $53.7 / 5.1$ & $4 / 638$ & 139 & 9 \\
\hline & & 240 & $53.7 / 5.1$ & $5 / 656$ & 169 & 12 \\
\hline \multirow{2}{*}{ VINC_HUMAN } & \multirow{2}{*}{ Vinculin } & 25 & $124.3 / 5.5$ & $14 / 578$ & 226 & 16 \\
\hline & & 27 & $124.3 / 5.5$ & $30 / 583$ & 643 & 25 \\
\hline
\end{tabular}

CD73, CD90, Annexin A2, and sphingosine kinase 1 (SPK1), additional studies were performed to investigate their expression in human PDLSC, GF, and keratinocytes (epithelial cell population). Flow cytometric analysis demonstrated high surface expression of CD73 and CD90 and low cell surface levels of Annexin A2 expression in human PDLSC and GF populations (Figure 2). In contrast, human keratinocytes showed a lack of cell surface expression for CD73, CD90, and Annexin A2 (Figure 2). Table 3 summarizes levels of surface expression of these four antigens on assessed cell types. In summary, CD73 and CD90 were expressed by human PDLSC and GF, but not by human keratinocytes, confirming that they are MSC-associated markers. Annexin A2 was demonstrated to be expressed at low levels by human 


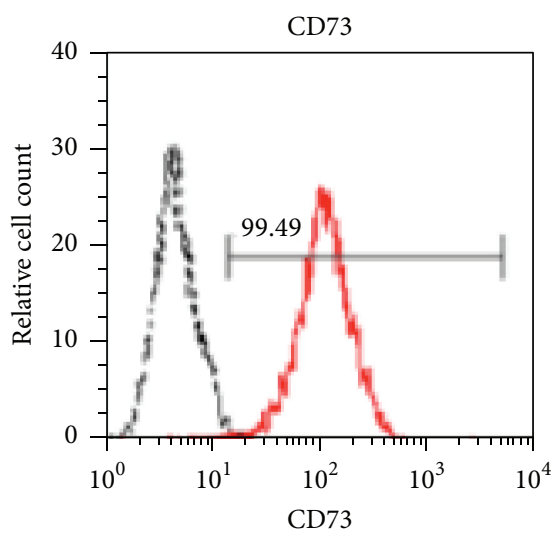

Fluorescence intensity

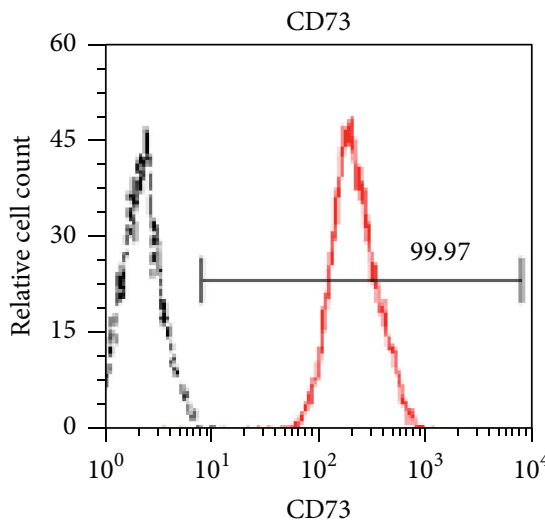

Fluorescence intensity

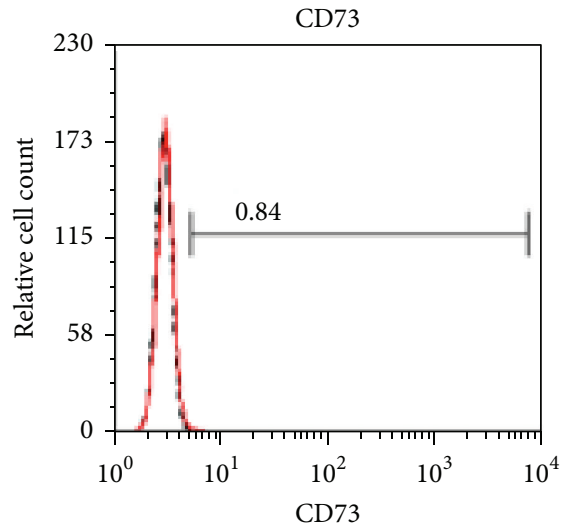

Fluorescence intensity

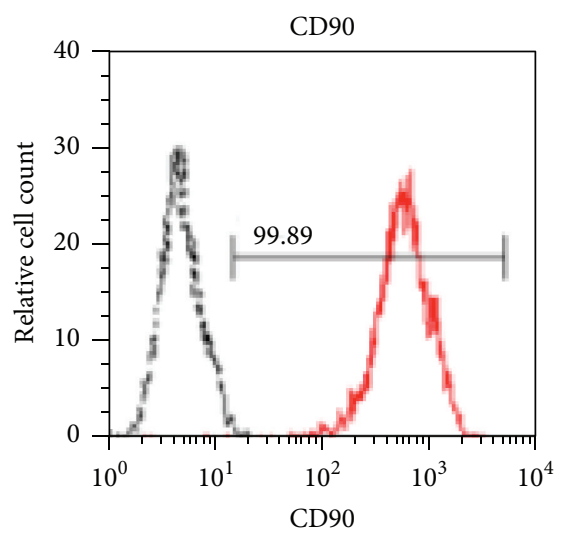

Fluorescence intensity

(a)

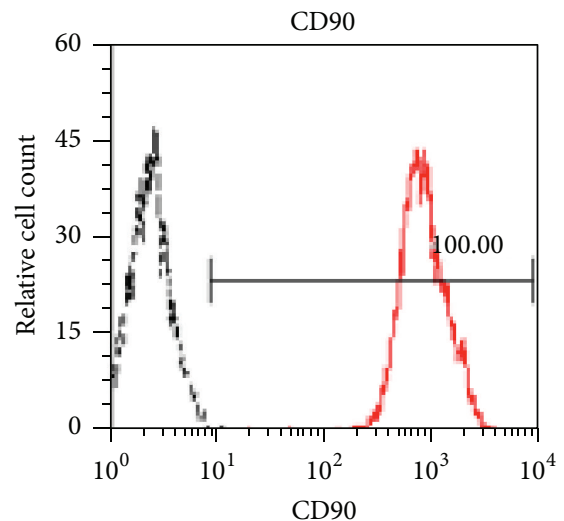

Fluorescence intensity

(b)

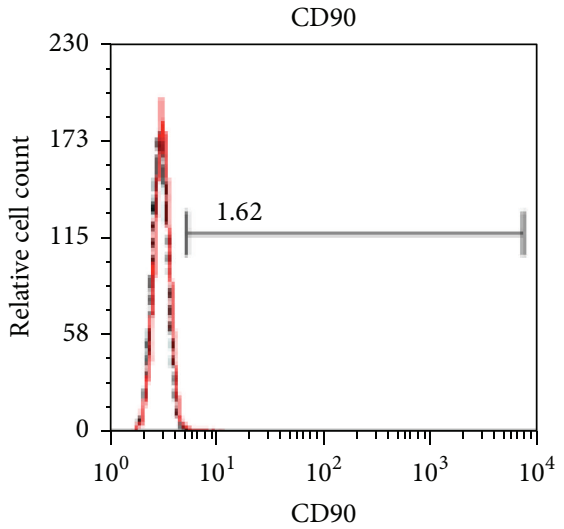

Fluorescence intensity

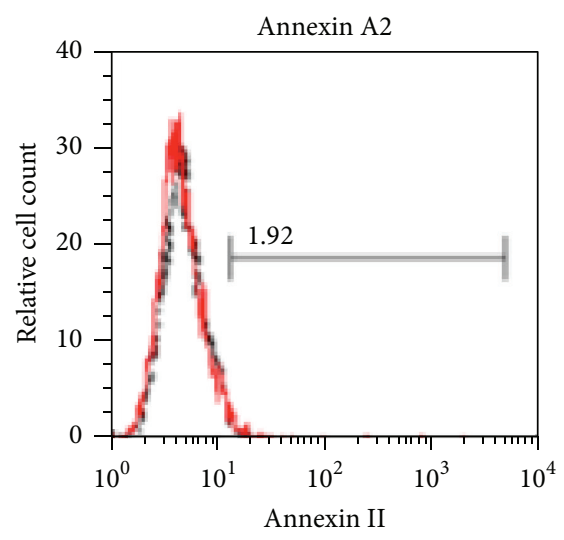

Fluorescence intensity

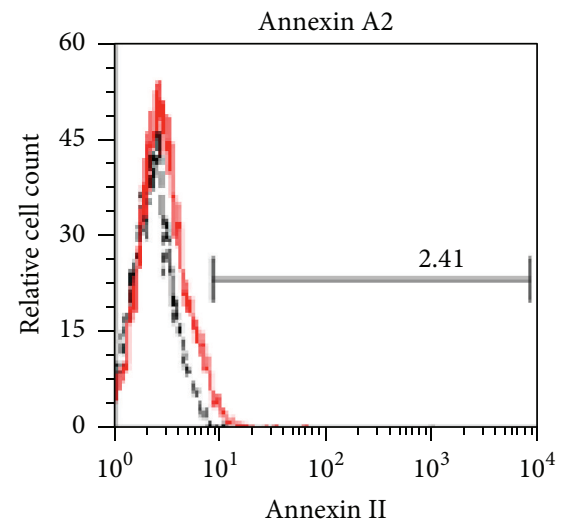

Fluorescence intensity

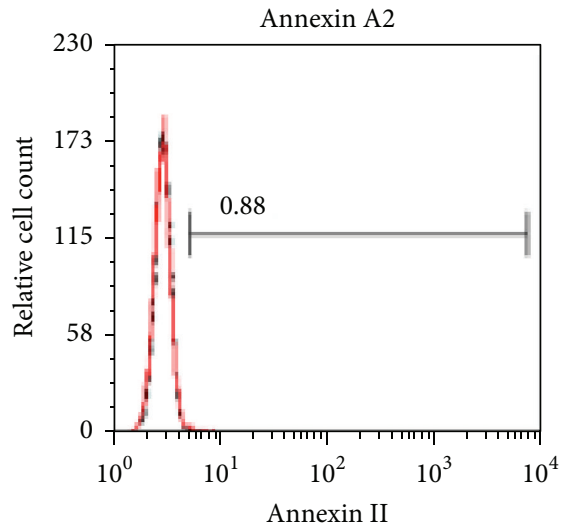

Fluorescence intensity

(c)

Figure 2: Validation of surface expression of CD73, CD90, and Annexin A2 using flow cytometric analysis in human (a) periodontal ligament stem cells, (b) gingival fibroblasts, and (c) skin keratinocytes.

PDLSC (1.92-7.83\%) and human GF (2.41-4.66\%), while human keratinocytes were largely negative for Annexin A2 expression (0.88-1.64\%). Previous studies have shown that SPK1 can translocate to the plasma membrane upon cell stimulation by cytokines [23-29]. No positive expression was detected with the anti-SPK1 antibody to the human cell types by flow cytometric analysis (data not shown), most likely because the available antibody reagent did not react with the extracellular domain of SPK1.

Additional studies were performed to investigate the expression of Annexin A2 and SPK1 in human PDLSC, GF, and keratinocytes, using immunocytochemistry. All cell types studied were positive to anti-Annexin A2 and anti-SPK1 antibodies (Figure 3 ). Of note, no reactivity was observed 
TABLE 3: Flow cytometric analysis of cell surface expression of CD73, CD90, and Annexin A2. Data represent median\% (range); $n=3$ replicate experiments.

\begin{tabular}{lccc}
\hline Antigen & PDLSC & GF & Keratinocytes \\
\hline \multirow{2}{*}{ CD73 } & $\mathbf{9 9 . 9 0}$ & $\mathbf{9 9 . 9 7}$ & $\mathbf{0 . 8 2}$ \\
& $(99.4-99.9)$ & $(99.9-100)$ & $(0.78-0.84)$ \\
\hline \multirow{2}{*}{ CD90 } & $\mathbf{9 9 . 9 8}$ & $\mathbf{9 9 . 9 8}$ & $\mathbf{1 . 5 8}$ \\
& $(99.8-100)$ & $(99.9-100)$ & $(1.55-1.62)$ \\
\hline \multirow{2}{*}{ Annexin A2 } & $\mathbf{4 . 4 8}$ & $\mathbf{2 . 9 2}$ & $\mathbf{0 . 8 6}$ \\
& $(1.92-7.83)$ & $(2.41-4.66)$ & $(0.86-1.64)$ \\
\hline
\end{tabular}

with the anti-CD73 or anti-CD90 antibodies to all cell types examined (data not shown), indicating that the specific epitopes identified by these antibodies were compromised following processing for immunocytochemical analysis.

\section{Discussion}

Initially, the first proteomic reference map of undifferentiated periodontal ligament fibroblasts identified 117 proteins, consistently expressed across three clones, which included a variety of expected cytoskeleton- and metabolism-related proteins [30]. This comparative analysis of the proteome revealed that the percentage of total cytoskeleton-related proteins identified in periodontal ligament fibroblasts (26.5\%) was higher than that in dermal fibroblasts (15\%). It was proposed that this difference is assigned to mechanical loading and rapid remodelling associated with periodontal ligament tissue [30].

Assessment of protein expression during differentiation of PDLSC identified 29 proteins, differentially expressed during early cementoblastic/osteogenic differentiation [31], and demonstrated a reduction in expression of cytoskeletal proteins and their binding partners, potentially attributed to cytoskeletal rearrangements during differentiation processes [32]. Interestingly, higher expression of the calciumbinding protein Annexin A4 was noted following osteogenic differentiation. Annexins are thought to play an important role in osteogenic development including Annexin A2 and Annexin A5 which are highly expressed in skeletal tissues and upregulated in osteogenic cultures of MSC [33,34].

A direct comparison of protein expression profiles between ovine PDLSC, DPSC, and BMSC identified 58 differentially expressed proteins between at least two MSC populations, with the expression of 6 proteins upregulated in PDLSC relative to both DPSC and BMSC, 5 proteins upregulated in DPSC relative to both PDLSC and BMSC, and 1 protein upregulated in BMSC relative to both PDLSC and DPSC [35]. An increase in PDLSC expression of heat-shock protein beta 1, Annexin A3, and Annexin A4 compared to DPSC and BMSC was thought to relate to high turnover of periodontal tissues.

The aim of the present study was to determine the surface expression profile of human PDLSC and to compare the expression of prospective cell surface markers in human PDLSC, GF, and keratinocytes (as a source of epithelial cells).
Our findings identified 80 proteins expressed on the surface of human PDLSC, 32 of which were membrane associated and four of which were selected for further validation due to their known association with other MSC-like populations as a proof-of-principal analysis. These include CD73 and CD90, well known MSC-associated markers, and Annexin A2 and SPK1. Annexin A2 is calcium dependent [36-42] and has been reported to be associated with the stem cell niche [4349] and SPK1 has recently been demonstrated to be associated with the progenitor phenotype of endothelial cells [50]. CD73 and CD90 were highly expressed by human PDLSC and GF but not by human keratinocytes, indicating that these antigens could be used as potential markers for distinguishing mesenchymal from epithelial cell populations. Annexin A2 was demonstratively expressed at the cell surface at low copy number by human PDLSC and GF, using flow cytometric analysis, while human keratinocytes lacked any cell surface expression of Annexin A2. Expression of SPK1 was detected in all analysed cell types using immunocytochemical analysis.

CD73, originally defined as a lymphocyte differentiation antigen, functions as a cosignalling molecule on $\mathrm{T}$ lymphocytes and is required for lymphocyte binding to endothelium [51]. Expression of CD73 has been demonstrated on various cell types including lymphocytes, endothelial cells, and MSC. It is thought to play physiological roles in epithelial ion and fluid transport, maintaining barrier functions, mediating endothelial permeability, adapting to hypoxia, and contributing to microbial responses [52]. CD73 is an extracellular enzyme that catalyzes the formation of immunosuppressive adenosine by converting adenosine $5^{\prime}$-monophosphate (AMP) to its bioactive intermediate, adenosine, which in turn activates adenosine receptors, when released into the extracellular space, and regulates various physiological functions $[52,53]$. Adenosine signalling, modulated by CD39 and CD73 expression, has been highlighted as a novel modulator in the immunosuppression of T-cell proliferation by MSC $[54,55]$. As such, this may be contributory to immunomodulatory properties of PDLSC [8] and may highlight an avenue for anti-inflammatory therapy in periodontal disease $[4,56]$.

The expression of CD90 on PDLSC has been well documented [56-59]; however, its role in PDLSC function remains largely unknown. CD90, also known as Thy-1 (thymocyte differentiation antigen-1), is found to be expressed in various cell types such as hematopoietic stem/progenitor cells [60], hepatic stem cells in human fetal liver [61], liver cancer stem cells [62], neurons, fibroblasts, vascular pericytes, and MSC [63]. Its expression is developmentally regulated [64] and remains one of the minimal criteria for defining human MSC, proposed by the committee for the International Society for Cellular Therapy (ISCT) $[63,65]$. While the biological role of CD90 is unclear, a number of associated immunological and nonimmunological functions have been previously addressed [64]. In addition to its involvement in T-cell activation [64], it is believed to be associated with many cellular processes and pathological conditions in a context-dependent manner [63], including cell-cell and cell-matrix interactions, cell motility, and thymocyte adhesion to epithelium [64]. Moreover, CD90 expression is also associated with fibroblast phenotypes relevant to wound healing and fibrosis. The differential 
Annexin A2

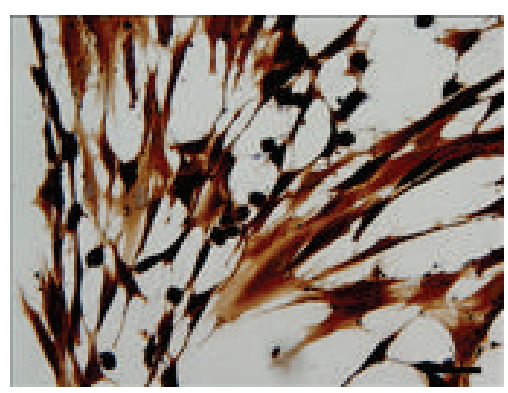

Annexin A2

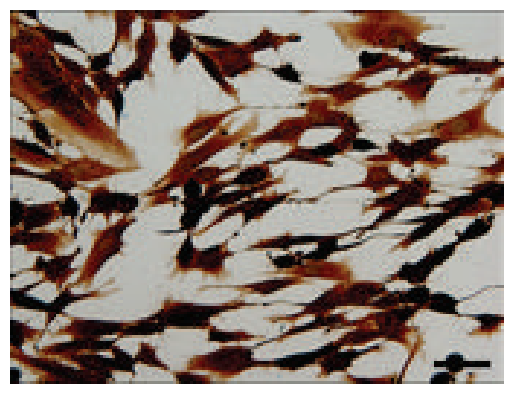

Annexin A2

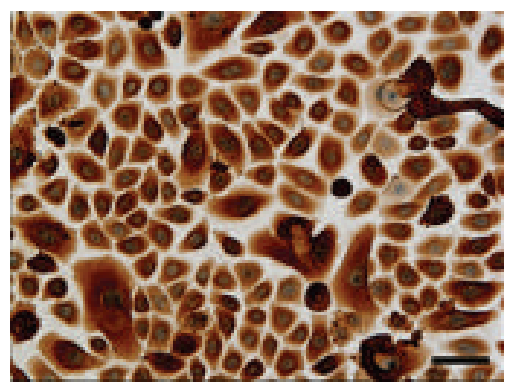

SPK1

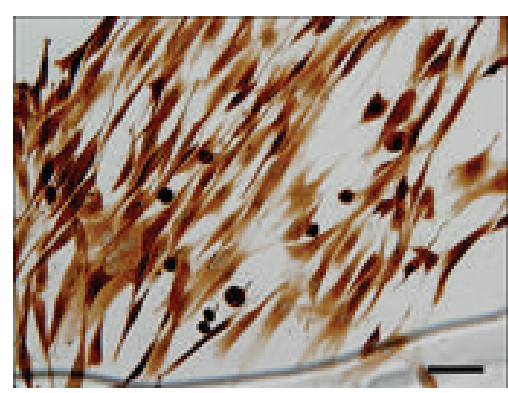

(a)

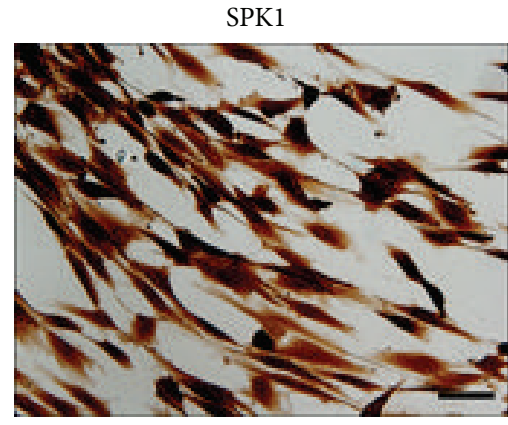

(b)

SPK1

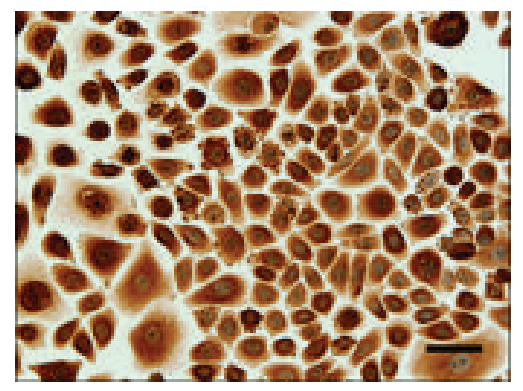

(c)

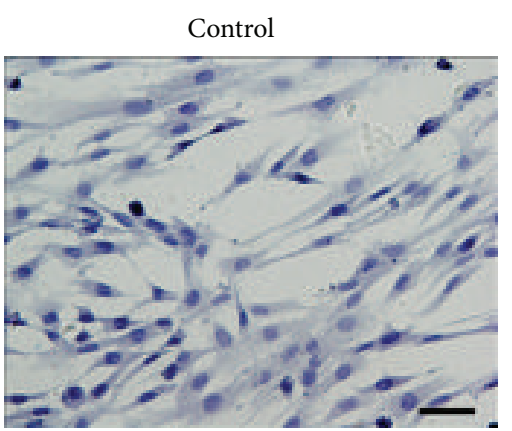

Control

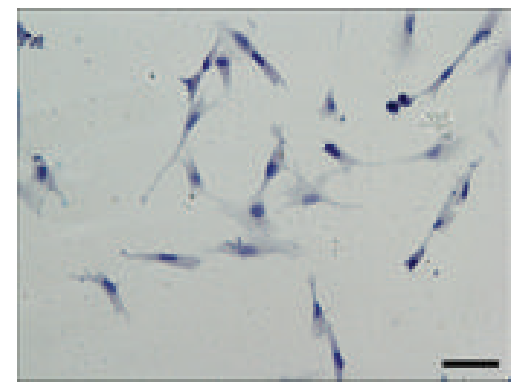

Control

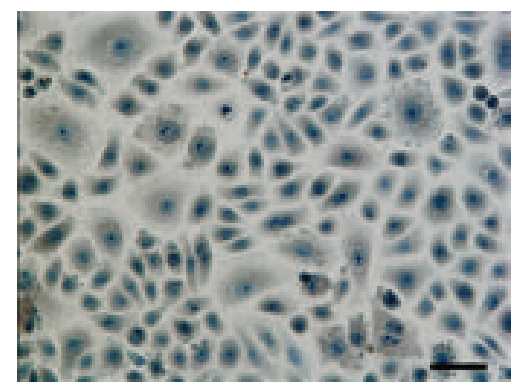

Figure 3: The expression of Annexin A2 and sphingosine kinase 1 (SPK1) in fixed and permeabilized (a) human periodontal ligament stem cells (PDLSC), (b) gingival fibroblasts (GF), and (c) keratinocytes using immunohistochemistry. All cell types studied were positive to antiAnnexin A2 and anti-SPK1 antibodies. Scale bar $=50 \mu \mathrm{m}$.

CD90 expression is associated with cell-extracellular matrix interactions and cell migration and, as such, is correlated with distinct cellular morphology [64].

Annexin A2, firstly identified as an intracellular protein, has since been found extracellularly both in secreted and in membrane bound form [66]. While Annexin A2 monomer is largely present in the cytoplasm, the formation of the heterotetramer allows its binding to the plasma membrane [6770]. Potential roles of extracellular Annexin A2 include plasminogen activation, cell-cell adhesion, and immunoglobulin transport [66]. Increasing evidence has highlighted the roles of the Annexin family of calcium-dependent, phopholipidbinding proteins in the mineralization process [36-42] and found them to be highly expressed in calcifying cartilage and bone and to serve to initiate mineralization of extracellular matrix [71]. Previously, it has been suggested that Annexin members also have the capacity to function in a compensatory manner of each other during skeletal development [72]. In a study investigating intracellular processes involved in mineralization, the overexpression of Annexin A2 has been shown to increase ALP activity and cartilage and bone formation, while diminished Annexin A2 expression resulted in decreased mineralization [38]. Collectively, previous findings related to Annexins in dental tissues are consistent with their roles in support of osteogenic differentiation and formation of minerals [31, 33, 35, 73, 74].

We identified Annexin A2 as one of the cell surface proteins expressed by human PDLSC. Further flow cytometric analysis showed the surface expression of Annexin A2 at low copy number by human GF. As a member of the Annexin family which plays important roles in the mineralization process [36-42], the low expression of Annexin A2 in 
human GF may be correlated to the fact that human GF demonstrated limited osteogenic potential when cultured in osteogenic conditions (data not shown). A recent study [75] suggested that Annexin A2 regulates adhesion, homing, and engraftment within stem cell niches at endosteal [43-47] and vascular $[48,49]$ sites; hence, we propose that it may be a potential marker of the PDLSC niche in periodontal tissues.

SPK1, the more characterised of the two SPK isoforms, enhances cell growth and proliferation and is involved in immune regulation and tumorigenesis [76]. This highly conserved lipid kinase catalyzes the phosphorylation of proapoptotic sphingosine to form antiapoptotic sphingosine1-phosphate (S1P) [77] and, as such, is an important cell fate determinant [78]. S1P is a key sphingolipid metabolite that regulates various physiological and pathological processes such as cell proliferation, differentiation, apoptosis, migration, invasion, and angiogenesis [78] and is thought to promote cell growth and proliferation and suppresses apoptosis [79]. In addition to their roles in regulating cell proliferation and apoptosis, SPK-S1P-S1P receptors have been shown to be involved in immune regulation such as immune cell trafficking, activation, and T-cell differentiation [77].

Multiple studies have demonstrated that SPK and S1P play important roles in the maintenance of stem cells [76] including endothelial progenitor cells, rate of endothelial progenitor cell differentiation [50, 80, 81], neural progenitors [82], human embryonic stem cells [76, 83], hematopoietic stem cell [76], and muscle progenitors [84]. Furthermore, SPK1 is a maker of oncogenic potential, tumour progression, and cancer prognosis in numerous tissue types $[85,86]$. It is predominantly a cytosolic enzyme, which lacks an obvious membrane anchoring sequence. However, considerable evidence has suggested that SPK1 can be translocated to the plasma membrane upon cell stimulation by growth factors and cytokines [23-25, 27-29, 83]. The present study initially identified SPK1 in human PDLSC by proteomic analysis and SPK1 expression was demonstrated in all cell types examined by immunocytochemical analysis. However, we were unable to demonstrate the cell surface expression of this enzyme, limited by the availability of an SPK1 antibody suitable for flow cytometry.

\section{Conclusion}

In summary, this study is the first, to date, to investigate the cell surface proteome of ex vivo expanded human PDLSC. In addition to the expression of recognised MSC-associated cell surface antigens CD73 and CD90, PDLSC were also found to express two novel cell surface proteins, Annexin A2 and sphingosine kinase 1 . Interestingly, previous studies have implicated CD73, CD90, Annexin A2, and sphingosine kinase 1 expression in the maintenance of various stem cell populations. Importantly, this study found that human skin epithelial cells lacked the expression of CD73, CD90, and Annexin A2. These proteomic findings provide the platform to further define the cell surface protein expression profile of PDLSC in order to further characterise this cell population and support development of novel isolation and purification strategies.

\section{Disclosure}

P. Mark Bartold and Stan Gronthos are co-senior authors.

\section{Competing Interests}

The authors declare that there are no competing interests regarding the publication of this paper.

\section{Acknowledgments}

This study was partly funded by NHMRC project Grant APP1043994, fellowship APP1042677, and ADRF Grant 37.2013 .

\section{References}

[1] T. Graf and M. Stadtfeld, "Heterogeneity of embryonic and adult stem cells," Cell Stem Cell, vol. 3, no. 5, pp. 480-483, 2008.

[2] M. Owen and A. J. Friedenstein, "Stromal stem cells: marrowderived osteogenic precursors," Ciba Foundation Symposium, vol. 136, pp. 42-60, 1988.

[3] S. Gronthos, A. C. W. Zannettino, S. E. Graves, S. Ohta, S. J. Hay, and P. J. Simmons, "Differential cell surface expression of the STRO-1 and alkaline phosphatase antigens on discrete developmental stages in primary cultures of human bone cells," Journal of Bone and Mineral Research, vol. 14, no. 1, pp. 47-56, 1999.

[4] B.-M. Seo, M. Miura, S. Gronthos et al., "Investigation of multipotent postnatal stem cells from human periodontal ligament," The Lancet, vol. 364, no. 9429, pp. 149-155, 2004.

[5] D. Menicanin, K. M. Mrozik, N. Wada et al., "Periodontalligament-derived stem cells exhibit the capacity for long-term survival, self-renewal, and regeneration of multiple tissue types in vivo," Stem Cells and Development, vol. 23, no. 9, pp. 1001-1011, 2014.

[6] S. C. Chen, V. Marino, S. Gronthos, and P. M. Bartold, "Location of putative stem cells in human periodontal ligament," Journal of Periodontal Research, vol. 41, no. 6, pp. 547-553, 2006.

[7] J. C. Rincon, W. G. Young, and P. M. Bartold, “The epithelial cell rests of Malassez-a role in periodontal regeneration?" Journal of Periodontal Research, vol. 41, no. 4, pp. 245-252, 2006.

[8] T. Iwata, M. Yamato, H. Tsuchioka et al., "Periodontal regeneration with multi-layered periodontal ligament-derived cell sheets in a canine model," Biomaterials, vol. 30, no. 14, pp. 27162723, 2009.

[9] P. M. Bartold, S. Shi, and S. Gronthos, "Stem cells and periodontal regeneration," Periodontology 2000, vol. 40, no. 1, pp. 164$172,2006$.

[10] C. A. G. McCulloch, "Progenitor cell populations in the periodontal ligament of mice," Anatomical Record, vol. 211, no. 3, pp. 258-262, 1985.

[11] C. A. G. McCulloch, E. Nemeth, B. Lowenberg, and A. H. Melcher, "Paravascular cells in endosteal spaces of alveolar bone contribute to periodontal ligament cell populations," Anatomical Record, vol. 219, no. 3, pp. 233-242, 1987.

[12] S. Yamada, S. Murakami, R. Matoba et al., "Expression profile of active genes in human periodontal ligament and isolation of PLAP-1, a novel SLRP family gene," Gene, vol. 275, no. 2, pp. 279-286, 2001. 
[13] Y. Saito, T. Yoshizawa, F. Takizawa et al., "A cell line with characteristics of the periodontal ligament fibroblasts is negatively regulated for mineralization and Runx2/Cbfa1/Osf2 activity, part of which can be overcome by bone morphogenetic protein2," Journal of Cell Science, vol. 115, no. 21, pp. 4191-4200, 2002.

[14] C. Morsczeck, G. Schmalz, T. E. Reichert, F. Völlner, K. Galler, and O. Driemel, "Somatic stem cells for regenerative dentistry," Clinical Oral Investigations, vol. 12, no. 2, pp. 113-118, 2008.

[15] C. A. McCulloch, "Proteomics for the periodontium: current strategies and future promise," Periodontology 2000, vol. 40, no. 1, pp. 173-183, 2006.

[16] Y. Zhang, T. Wang, W. Chen et al., "Differential protein expression by Porphyromonas gingivalis in response to secreted epithelial cell components," Proteomics, vol. 5, no. 1, pp. 198-211, 2005.

[17] Q. Xia, T. Wang, F. Taub et al., "Quantitative proteomics of intracellular Porphyromonas gingivalis," Proteomics, vol. 7, no. 23, pp. 4323-4337, 2007.

[18] P. D. Veith, G. H. Talbo, N. Slakeski, and E. C. Reynolds, "Identification of a novel heterodimeric outer membrane protein of Porphyromonas gingivalis by two-dimensional gel electrophoresis and peptide mass fingerprinting," European Journal of Biochemistry, vol. 268, no. 17, pp. 4748-4757, 2001.

[19] M. J. Somerman, S. Y. Archer, G. R. Imm, and R. A. Foster, "A comparative study of human periodontal ligament cells and gingival fibroblasts in vitro," Journal of Dental Research, vol. 67, no. 1, pp. 66-70, 1988.

[20] C. Mayrhofer, S. Krieger, G. Allmaier, and D. Kerjaschki, "DIGE compatible labelling of surface proteins on vital cells in vitro and in vivo," Proteomics, vol. 6, no. 2, pp. 579-585, 2006.

[21] P. S. Zilm, A. Mira, C. J. Bagley, and A. H. Rogers, "Effect of alkaline growth $\mathrm{pH}$ on the expression of cell envelope proteins in Fusobacterium nucleatum," Microbiology, vol. 156, part 6, pp. 1783-1794, 2010.

[22] A. Gorg, G. Boguth, C. Obermaier, and W. Weiss, "Twodimensional electrophoresis of proteins in an immobilized $\mathrm{pH}$ 4-12 gradient," Electrophoresis, vol. 19, no. 8-9, pp. 1516-1519, 1998.

[23] N. Ancellin, C. Colmont, J. Su et al., "Extracellular export of sphingosine kinase-1 enzyme. Sphingosine 1-phosphate generation and the induction of angiogenic vascular maturation," The Journal of Biological Chemistry, vol. 277, no. 8, pp. 6667-6675, 2002.

[24] J. A. Hengst, J. M. Guilford, T. E. Fox, X. Wang, E. J. Conroy, and J. K. Yun, "Sphingosine kinase 1 localized to the plasma membrane lipid raft microdomain overcomes serum deprivation induced growth inhibition," Archives of Biochemistry and Biophysics, vol. 492, no. 1-2, pp. 62-73, 2009.

[25] K. E. Jarman, P. A. B. Moretti, J. R. Zebol, and S. M. Pitson, "Translocation of sphingosine kinase 1 to the plasma membrane is mediated by calcium- and integrin-binding protein 1," Journal of Biological Chemistry, vol. 285, no. 1, pp. 483-492, 2010.

[26] S. M. Pitson, P. Xia, T. M. Leclercq et al., "Phosphorylationdependent translocation of sphingosine kinase to the plasma membrane drives its oncogenic signalling," The Journal of Experimental Medicine, vol. 201, no. 1, pp. 49-54, 2005.

[27] R. V. Stahelin, J. H. Hwang, J.-H. Kim et al., "The mechanism of membrane targeting of human sphingosine kinase 1," The Journal of Biological Chemistry, vol. 280, no. 52, pp. 4303043038, 2005.
[28] B. W. Wattenberg, "Role of sphingosine kinase localization in sphingolipid signaling," World Journal of Biological Chemistry, vol. 1, no. 12, pp. 362-368, 2010.

[29] K. W. Young, J. M. Willets, M. J. Parkinson et al., " $\mathrm{Ca}^{2+} /$ calmodulin-dependent translocation of sphingosine kinase: role in plasma membrane relocation but not activation," Cell Calcium, vol. 33, no. 2, pp. 119-128, 2003.

[30] E. Reichenberg, M. Redlich, P. Cancemi et al., "Proteomic analysis of protein components in periodontal ligament fibroblasts," Journal of Periodontology, vol. 76, no. 10, pp. 1645-1653, 2005.

[31] L. Wu, X. Wei, J. Ling et al., "Early osteogenic differential protein profile detected by proteomic analysis in human periodontal ligament cells," Journal of Periodontal Research, vol. 44, no. 5, pp. 645-656, 2009.

[32] L. J. Foster, P. A. Zeemann, C. Li, M. Mann, O. N. Jensen, and M. Kassem, "Differential expression profiling of membrane proteins by quantitative proteomics in a human mesenchymal stem cell line undergoing osteoblast differentiation," Stem Cells, vol. 23, no. 9, pp. 1367-1377, 2005.

[33] A.-X. Zhang, W.-H. Yu, B.-F. Ma et al., "Proteomic identification of differently expressed proteins responsible for osteoblast differentiation from human mesenchymal stem cells," Molecular and Cellular Biochemistry, vol. 304, no. 1-2, pp. 167-179, 2007.

[34] H. J. Sun, Y. Y. Bahk, Y. R. Choi, J. H. Shim, S. H. Han, and J. W. Lee, "A proteomic analysis during serial subculture and osteogenic differentiation of human mesenchymal stem cell," Journal of Orthopaedic Research, vol. 24, no. 11, pp. 2059-2071, 2006.

[35] K. M. Mrozik, P. S. Zilm, C. J. Bagley et al., "Proteomic characterization of mesenchymal stem cell-like populations derived from ovine periodontal ligament, dental pulp, and bone marrow: analysis of differentially expressed proteins," Stem Cells and Development, vol. 19, no. 10, pp. 1485-1499, 2010.

[36] M. Balcerzak, E. Hamade, L. Zhang et al., "The roles of annexins and alkaline phosphatase in mineralization process," Acta Biochimica Polonica, vol. 50, no. 4, pp. 1019-1038, 2003.

[37] D. C. Genetos, A. Wong, S. Watari, and C. E. Yellowley, "Hypoxia increases Annexin A2 expression in osteoblastic cells via VEGF and ERK," Bone, vol. 47, no. 6, pp. 1013-1019, 2010.

[38] J. M. Gillette and S. M. Nielsen-Preiss, "The role of annexin 2 in osteoblastic mineralization," Journal of Cell Science, vol. 117, no. 3, pp. 441-449, 2004.

[39] T. L. Haut Donahue, D. C. Genetos, C. R. Jacobs, H. J. Donahue, and C. E. Yellowley, "Annexin V disruption impairs mechanically induced calcium signaling in osteoblastic cells," Bone, vol. 35, no. 3, pp. 656-663, 2004.

[40] T. Kirsch, B. Swoboda, and H.-D. Nah, "Activation of annexin II and $\mathrm{V}$ expression, terminal differentiation, mineralization and apoptosis in human osteoarthritic cartilage," Osteoarthritis and Cartilage, vol. 8, no. 4, pp. 294-302, 2000.

[41] D. Pfander, B. Swoboda, and T. Kirsch, "Expression of early and late differentiation markers (proliferating cell nuclear antigen, syndecan-3, annexin VI, and alkaline phosphatase) by human osteoarthritic chondrocytes," American Journal of Pathology, vol. 159, no. 5, pp. 1777-1783, 2001.

[42] W. Wang and T. Kirsch, "Retinoic acid stimulates annexinmediated growth plate chondrocyte mineralization," The Journal of Cell Biology, vol. 157, no. 6, pp. 1061-1069, 2002.

[43] J. Zhang, C. Niu, L. Ye et al., "Identification of the haematopoietic stem cell niche and control of the niche size," Nature, vol. 425, no. 6960, pp. 836-841, 2003. 
[44] S. Stier, Y. Ko, R. Forkert et al., "Osteopontin is a hematopoietic stem cell niche component that negatively regulates stem cell pool size," The Journal of Experimental Medicine, vol. 201, no. 11, pp. 1781-1791, 2005.

[45] S. K. Nilsson, H. M. Johnston, G. A. Whitty et al., "Osteopontin, a key component of the hematopoietic stem cell niche and regulator of primitive hematopoietic progenitor cells," Blood, vol. 106, no. 4, pp. 1232-1239, 2005.

[46] L. M. Calvi, G. B. Adams, K. W. Weibrecht et al., "Osteoblastic cells regulate the haematopoietic stem cell niche," Nature, vol. 425, no. 6960, pp. 841-846, 2003.

[47] F. Arai, A. Hirao, M. Ohmura et al., "Tie2/angiopoietin-1 signaling regulates hematopoietic stem cell quiescence in the bone marrow niche," Cell, vol. 118, no. 2, pp. 149-161, 2004.

[48] S. T. Avecilla, K. Hattori, B. Heissig et al., "Chemokine-mediated interaction of hematopoietic progenitors with the bone marrow vascular niche is required for thrombopoiesis," Nature Medicine, vol. 10, no. 1, pp. 64-71, 2004.

[49] M. J. Kiel, Ö. H. Yilmaz, T. Iwashita, O. H. Yilmaz, C. Terhorst, and S. J. Morrison, "SLAM family receptors distinguish hematopoietic stem and progenitor cells and reveal endothelial niches for stem cells," Cell, vol. 121, no. 7, pp. 1109-1121, 2005.

[50] J. M. Barrett, K. A. Parham, J. B. Pippal et al., "Over-expression of sphingosine kinase-1 enhances a progenitor phenotype in human endothelial cells," Microcirculation, vol. 18, no. 7, pp. 583-597, 2011.

[51] B. Zhang, "CD73: a novel target for cancer immunotherapy," Cancer Research, vol. 70, no. 16, pp. 6407-6411, 2010.

[52] S. P. Colgan, H. K. Eltzschig, T. Eckle, and L. F. Thompson, "Physiological roles for ecto-5/-nucleotidase (CD73)," Purinergic Signalling, vol. 2, no. 2, pp. 351-360, 2006.

[53] P. A. Beavis, J. Stagg, P. K. Darcy, and M. J. Smyth, "CD73: a potent suppressor of antitumor immune responses," Trends in Immunology, vol. 33, no. 5, pp. 231-237, 2012.

[54] C. Sattler, M. Steinsdoerfer, M. Offers et al., "Inhibition of T-cell proliferation by murine multipotent mesenchymal stromal cells is mediated by CD39 expression and adenosine generation," Cell Transplantation, vol. 20, no. 8, pp. 1221-1230, 2011.

[55] F. Saldanha-Araujo, F. I. S. Ferreira, P. V. Palma et al., "Mesenchymal stromal cells up-regulate CD39 and increase adenosine production to suppress activated T-lymphocytes," Stem Cell Research, vol. 7, no. 1, pp. 66-74, 2011.

[56] N. Wada, D. Menicanin, S. Shi, P. M. Bartold, and S. Gronthos, "Immunomodulatory properties of human periodontal ligament stem cells," Journal of Cellular Physiology, vol. 219, no. 3, pp. 667-676, 2009.

[57] T. Kato, K. Hattori, T. Deguchi et al., "Osteogenic potential of rat stromal cells derived from periodontal ligament," Journal of Tissue Engineering and Regenerative Medicine, vol. 5, no. 10, pp. 798-805, 2011.

[58] A. Tomokiyo, H. Maeda, S. Fujii et al., "A multipotent clonal human periodontal ligament cell line with neural crest cell phenotypes promotes neurocytic differentiation, migration, and survival," Journal of Cellular Physiology, vol. 227, no. 5, pp. 2040-2050, 2012.

[59] O. Trubiani, S. F. Zalzal, R. Paganelli et al., "Expression profile of the embryonic markers nanog, OCT-4, SSEA-1, SSEA-4, and frizzled-9 receptor in human periodontal ligament mesenchymal stem cells," Journal of Cellular Physiology, vol. 225, no. 1, pp. 123-131, 2010.
[60] C. M. Baum, I. L. Weissman, A. S. Tsukamoto, A.-M. Buckle, and B. Peault, "Isolation of a candidate human hematopoietic stem-cell population," Proceedings of the National Academy of Sciences of the United States of America, vol. 89, no. 7, pp. 28042808, 1992.

[61] N. M. Masson, I. S. Currie, J. D. Terrace, O. J. Garden, R. W. Parks, and J. A. Ross, "Hepatic progenitor cells in human fetal liver express the oval cell marker Thy-1," American Journal of Physiology-Gastrointestinal and Liver Physiology, vol. 291, no. 1, pp. G45-G54, 2006.

[62] Z. F. Yang, D. W. Ho, M. N. Ng et al., "Significance of CD90+ cancer stem cells in human liver cancer," Cancer Cell, vol. 13, no. 2, pp. 153-166, 2008.

[63] J. E. Bradley, G. Ramirez, and J. S. Hagood, "Roles and regulation of Thy-1, a context-dependent modulator of cell phenotype," BioFactors, vol. 35, no. 3, pp. 258-265, 2009.

[64] S. M. M. Haeryfar and D. W. Hoskin, "Thy-1: more than a mouse pan-T cell marker," Journal of Immunology, vol. 173, no. 6, pp. 3581-3588, 2004.

[65] M. Dominici, K. Le Blanc, I. Mueller et al., "Minimal criteria for defining multipotent mesenchymal stromal cells. The International Society for Cellular Therapy position statement," Cytotherapy, vol. 8, no. 4, pp. 315-317, 2006.

[66] D. A. Siever and H. P. Erickson, "Extracellular annexin II," International Journal of Biochemistry and Cell Biology, vol. 29, no. 11, pp. 1219-1223, 1997.

[67] N. Zobiack, V. Gerke, and U. Rescher, "Complex formation and submembranous localization of annexin 2 and S100A10 in live HepG2 cells," FEBS Letters, vol. 500, no. 3, pp. 137-140, 2001.

[68] J. R. Glenney Jr., "Co-precipitation of intestinal p36 with a $73 \mathrm{~K}$ protein and a high molecular weight factor," Experimental Cell Research, vol. 162, no. 1, pp. 183-190, 1986.

[69] V. Gerke and K. Weber, "Identity of p36K phosphorylated upon Rous sarcoma virus transformation with a protein purified from brush borders; calcium-dependent binding to non-erythroid spectrin and F-actin," The EMBO Journal, vol. 3, no. 1, pp. 227233, 1984.

[70] C. Thiel, M. Osborn, and V. Gerke, "The tight association of the tyrosine kinase substrate annexin II with the submembranous cytoskeleton depends on intact p11- and Ca2+-binding sites," Journal of Cell Science, vol. 103, no. 3, pp. 733-742, 1992.

[71] H. C. Anderson, "Molecular biology of matrix vesicles," Clinical Orthopaedics and Related Research, no. 314, pp. 266-280, 1995.

[72] B. Brachvogel, J. Dikschas, H. Moch et al., "Annexin A5 is not essential for skeletal development," Molecular and Cellular Biology, vol. 23, no. 8, pp. 2907-2913, 2003.

[73] K. Yuan, J.-S. Huang, C.-W. Hsu, and I.-J. Hung, "A mineralization-associated membrane protein plays a role in the biological functions of the peptide-coated bovine hydroxyapatite," Journal of Periodontal Research, vol. 42, no. 5, pp. 420-428, 2007.

[74] D. Bozic, L. Grgurevic, I. Erjavec et al., "The proteome and gene expression profile of cementoblastic cells treated by bone morphogenetic protein-7 in vitro," Journal of Clinical Periodontology, vol. 39, no. 1, pp. 80-90, 2012.

[75] Y. Jung, J. Wang, J. Song et al., “Annexin II expressed by osteoblasts and endothelial cells regulates stem cell adhesion, homing, and engraftment following transplantation," Blood, vol. 110, no. 1, pp. 82-90, 2007.

[76] A. Pébay, C. S. Bonder, and S. M. Pitson, "Stem cell regulation by lysophospholipids," Prostaglandins and Other Lipid Mediators, vol. 84, no. 3-4, pp. 83-97, 2007. 
[77] H. Chi, "Sphingosine-1-phosphate and immune regulation: trafficking and beyond," Trends in Pharmacological Sciences, vol. 32, no. 1, pp. 16-24, 2011.

[78] A. Olivera and S. Spiegel, "Sphingosine kinase: a mediator of vital cellular functions," Prostaglandins and Other Lipid Mediators, vol. 64, no. 1-4, pp. 123-134, 2001.

[79] S. Spiegel, O. Cuvillier, L. C. Edsall et al., "Sphingosine-1phosphate in cell growth and cell death," Annals of the New York Academy of Sciences, vol. 845, pp. 11-8, 1998.

[80] V. Limaye, X. Li, C. Hahn et al., "Sphingosine kinase-1 enhances endothelial cell survival through a PECAM-1-dependent activation of PI-3K/Akt and regulation of Bcl-2 family members," Blood, vol. 105, no. 8, pp. 3169-3177, 2005.

[81] C. S. Bonder, W. Y. Sun, T. Matthews et al., "Sphingosine kinase regulates the rate of endothelial progenitor cell differentiation," Blood, vol. 113, no. 9, pp. 2108-2117, 2009.

[82] H. Meng, Y. Yuan, and V. M. Lee, "Loss of Sphingosine kinase 1/S1P signaling impairs cell growth and survival of neurons and progenitor cells in the developing sensory ganglia," PLoS ONE, vol. 6, no. 11, Article ID e27150, 2011.

[83] A. Pébay, R. C. B. Wong, S. M. Pitson et al., "Essential roles of sphingosine-1-phosphate and platelet-derived growth factor in the maintenance of human embryonic stem cells," Stem Cells, vol. 23, no. 10, pp. 1541-1548, 2005.

[84] Y. Nagata, T. A. Partridge, R. Matsuda, and P. S. Zammit, "Entry of muscle satellite cells into the cell cycle requires sphingolipid signaling," The Journal of Cell Biology, vol. 174, no. 2, pp. 245253, 2006.

[85] P. Xia, J. R. Gamble, L. Wang et al., "An oncogenic role of sphingosine kinase," Current Biology, vol. 10, no. 23, pp. 15271530, 2000.

[86] D. Shida, K. Takabe, D. Kapitonov, S. Milstien, and S. Spiegel, "Targeting SphK1 as a new strategy against cancer," Current Drug Targets, vol. 9, no. 8, pp. 662-673, 2008. 

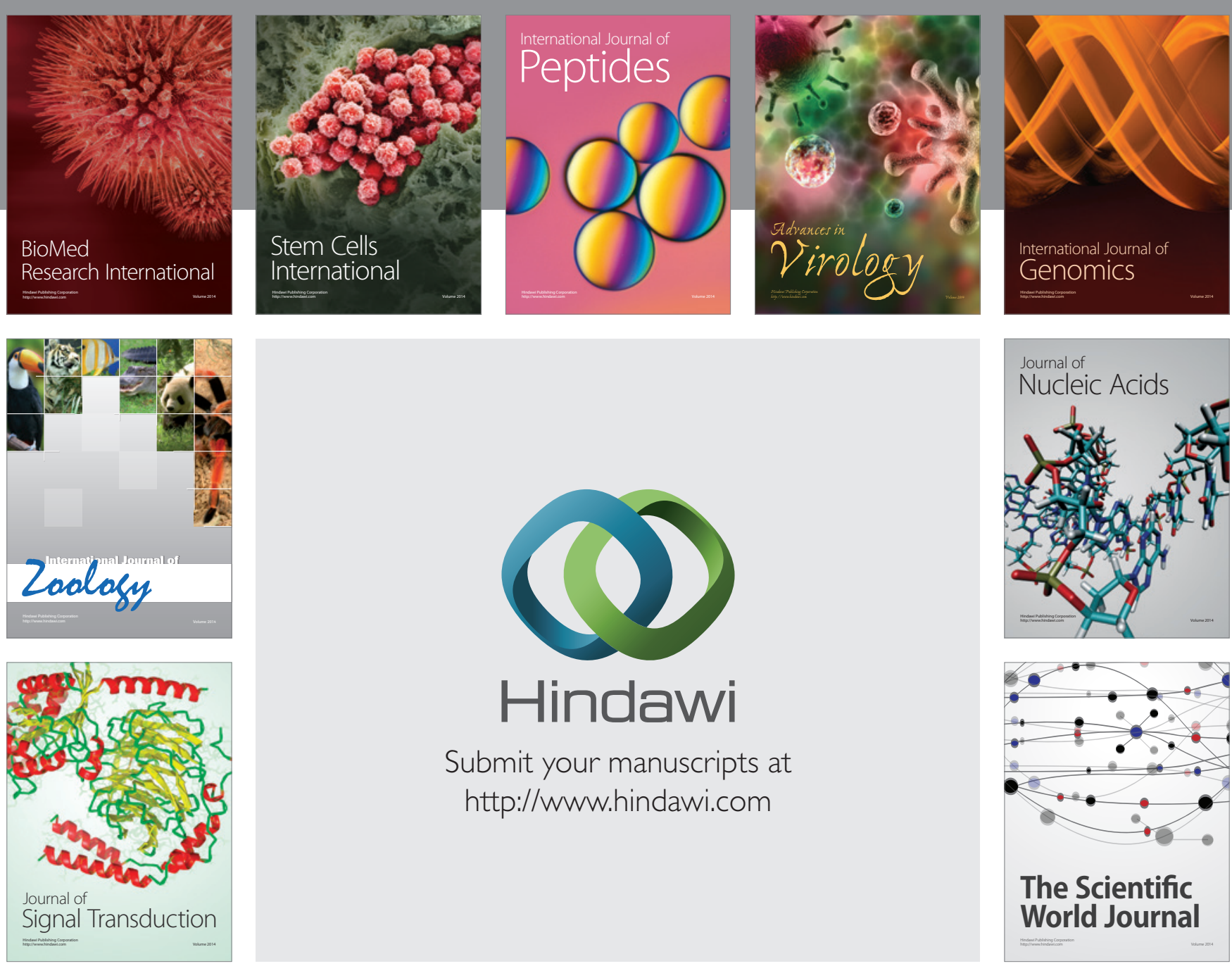

Submit your manuscripts at

http://www.hindawi.com
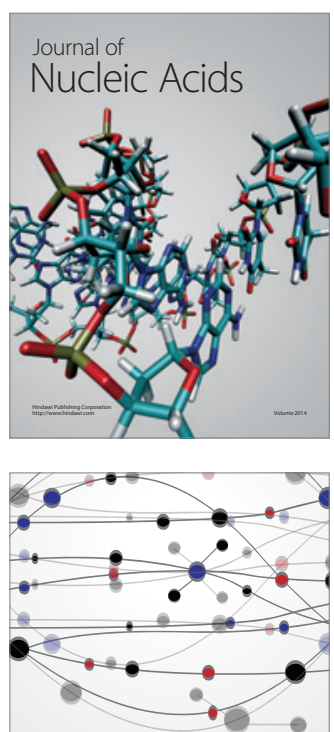

The Scientific World Journal
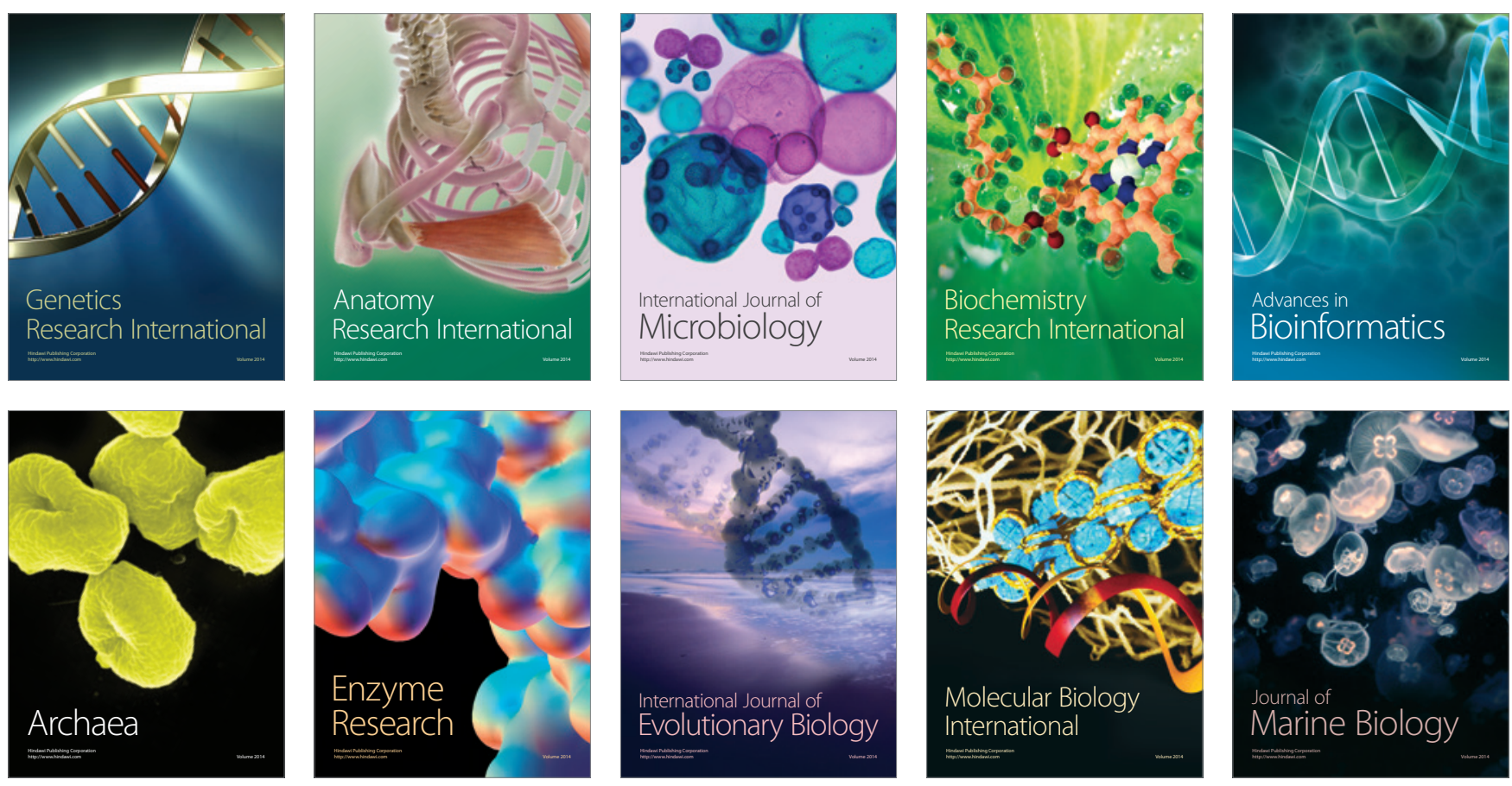